\title{
Effects of Air Velocity, Air Gap Thickness and Configuration on Heat Transfer of a Wearable Convective Cooling System
}

\author{
Yu Sun, Warren J Jasper and Emiel A DenHartog* \\ Department of Textile Engineering, Chemistry and Science, North Carolina State University, USA
}

\begin{abstract}
The effects of air velocity, air-gap thickness and configuration on heat transfer of a wearable convective cooling system were modeled using a 2-D Computational Fluid Dynamics (CFD) simulation. Three different configurations, one with eight $1 \mathrm{~cm}$ fans $(8 \times 1$ model); one with four $2 \mathrm{~cm}$ fans $(4 \times 2$ model); and one with four $1 \mathrm{~cm}$ fans $(4 \times 1$ model) were studied at different inlet air velocities of $0.25 \mathrm{~m} / \mathrm{s}, 0.5 \mathrm{~m} / \mathrm{s}, 0.75 \mathrm{~m} / \mathrm{s}$ and $1.0 \mathrm{~m} / \mathrm{s}$ and with air gaps of 3 $\mathrm{mm}, 7 \mathrm{~mm}$ and $11 \mathrm{~mm}$. The simulations showed that the convective and evaporative heat transfer coefficients varied with a power function of inlet air velocity, but the exponent was larger than reported in the literature. At lower air velocities, the heat transfer coefficients increased as the gap between the skin and the undergarment widened. At higher inlet air velocities, $3 \mathrm{~mm}$ and $11 \mathrm{~mm}$ air gaps showed the highest heat transfer values. The ratios of the heat transfer coefficients of the $8 \times 1$ and $4 \times 2$ models to the $4 \times 1$ models were both less than 2 indicating that doubling the inlet airflow does not double the heat transfer capability. The ratios of convective to evaporative heat transfer coefficients were around $8.63 \mathrm{~K} / \mathrm{kPa}(\mathrm{SD} 0.25 \mathrm{~K} / \mathrm{kPa})$, and were independent on the air velocity and configurations of the cooling system, suggesting that convective and evaporative heat transfer are fully coupled. This ratio also shows that the vapor permeability index of our system is around 0.52 . Using slightly larger fans should be more effective in enhancing heat transfer than using more fans.
\end{abstract}

Keywords: Wearable cooling system; Convective heat transfer; Evaporative heat transfer; Vapor permeability; Simulation

\section{Introduction}

Personal cooling systems have been the focus of many research studies, which primarily reported the reduction of heat strain in protective clothing systems used by the military and fire fighters. Personal cooling systems are beneficial to these groups as well as industrial workers providing safety, health and comfort in hot or hazardous environments. However, wearable personal cooling systems can also provide occupants in office buildings with an increased comfort range, e.g., in buildings and rooms that have insufficient or reduced air-conditioning in the summer months. With wearable personal cooling systems, energy could potentially be saved by reducing the airconditioning usage without compromising thermal comfort.

Currently, personal cooling systems can be divided into three basic types [1]: air ventilation systems; liquid/gas cooling systems and phase change material (PCM) systems. Although hybrid systems that combine liquid and evaporative cooling exist as well, the classification into these three base technologies helps define the pros and cons of these different cooling technologies. In PCM systems, phase change materials are incorporated into the clothing system, either in bulk or integrated into the fiber/yarn, and the cooling effects are caused by the latent heat that is absorbed to melt the PCM materials. One of the disadvantages of PCM is the temporary cooling effect [1-5]. Lu et al. studied the cooling effects of a PCM with 24 pieces of cooling pads filled with $2.06 \mathrm{~kg}$ sodium sulphate decahydrate [5]. It was found that the duration of the cooling is only around 19 to 78 minutes [5]. Another shortcoming of the PCM is the storage of phase change materials. Some investigators placed several bags filled with phase change materials into the packets of clothing. However, these bags can be an insulation of sweating evaporation thus inhibited the evaporative heat loss [1]. Some other researchers made the phase change materials into a micro-capsulate form and incorporated them into the void space between the yarns in the fabrics of the garment. But this would cause a complicated manufacturing process and relatively high cost with very limited effects because of the low amount of PCM in fabrics that should be wearable [1-2]. In the liquid/gas cooling systems, tubes filled with a refrigerated liquid or gas are worn on or close to the skin, depending on the temperature. The liquid/gas filled tubes are often connected to small refrigerating units, which provide the cooled liquids/gas [6-9]. Liquid/gas cooling garments have limited wearability and are not considered energy efficient.

In air ventilation systems, cooling is provided by convective and evaporative heat loss via ventilation. Published research [10-18] on air ventilation systems has primarily focused on reducing thermal stress in warm environments $\left(35^{\circ} \mathrm{C}-40^{\circ} \mathrm{C}\right)$ where evaporative cooling from sweat is still realistic. Depending on the blower units used, the ventilation system may be fairly heavy ( $1 \mathrm{~kg}-4 \mathrm{~kg}$ ), limiting the wearability of such systems in office environments. New technology developments, however, allow for the use of very small fans that consume low power and have low weight. This would allow for the development of wearable air cooling systems for office workers at moderately higher temperatures $\left(27^{\circ} \mathrm{C}-30^{\circ} \mathrm{C}\right)$, if the fan's small flow rates could provide sufficient cooling to maintain comfort outside the regular comfort temperature range. Zhao et al. and $\mathrm{Lu}$ et al. developed a 0.6 cooling garment $(0.6$ $\mathrm{kg}$ ) attached with four $10 \mathrm{~cm}$ fans at the belly and back parts $[5,17,18]$ However, the fans were still too large for everyday wear and should be made smaller and lighter to improve the cooling systems' wearability and portability for provide enough cooling power at moderate warm environment $\left(27^{\circ} \mathrm{C}-30^{\circ} \mathrm{C}\right)$. In our previous study [19], we developed a simulation model for a wearable convective cooling system consisting

*Corresponding author: Emiel A DenHartog, College of Textiles, North Carolina State University, 2401 Research drive, Campus Box 8301 Raleigh, USA, Tel: +1 919515 6659; E-mail: eadenhar@ncsu.edu

Received November 17, 2015; Accepted December 10, 2015; Published December 17, 2015

Citation: Sun Y, Jasper WJ, DenHartog EA (2015) Effects of Air Velocity, Air Gap Thickness and Configuration on Heat Transfer of a Wearable Convective Cooling System. J Textile Sci Eng 5: 227. doi:10.4172/2165-8064.1000227

Copyright: ( 2015 Sun Y, et al. This is an open-access article distributed under the terms of the Creative Commons Attribution License, which permits unrestricted use, distribution, and reproduction in any medium, provided the original author and source are credited. 
a $40 \mathrm{~cm}$ long textile ribbon fabricated with 4 or 8 fans of $1 \mathrm{~cm}$ or $2 \mathrm{~cm}$ size. These ribbons are designed to provide air velocities of up to $1 \mathrm{~m} / \mathrm{s}$ in the gap between the skin and an undergarment. A two dimensional computational fluid dynamics (CFD) model was developed utilizing COMSOL Multiphysics to simulate airflow as well as the convective heat and moisture transfer in the air gap, and to obtain the convective and evaporative heat loss at the skin surface.

Our previous study [19] was focused on procedures for the construction and simulation of a two-dimensional model. In this study, we will show more detailed results which will focus on the effects of airflow velocity, air gaps between the skin surface and undergarment on heat transfer, the effect of fan size and quantity on heat transfer, to identify the design criteria to optimize heat loss.

\section{Methods}

\section{Mathematical modeling of wearable convective cooling system}

The wearable convective cooling system shown in Figure 1 consists of a $40 \mathrm{~cm}$ long by $2 \mathrm{~cm}-3 \mathrm{~cm}$ wide textile ribbon in which 4 to 8 fans are embedded. The technology is based on miniature battery-powered blowers embedded in fabric ribbons worn underneath a garment. Fan size is a critical parameter: fans must be large enough to augment body cooling and yet be sufficiently small so that the ribbons are comfortable and non-intrusive. Furthermore, fans become less efficient at moving air as their size is reduced because frictional losses dominate at small scales. This study was also used to determine effects of fan size. Fan performance is characterized by several parameters, including pressure (P) and air volume flow (Q'). In our 2-D simulations, the air flow per unit area (Q'/A) is simply the air velocity the fans generate. Using representative data from manufacturers of miniature fans, the expected maximum air velocity for fans with a $1 \mathrm{~cm}$ to $2 \mathrm{~cm}$ diameter would be in the range of $0.25 \mathrm{~m} / \mathrm{s}$ to $1 \mathrm{~m} / \mathrm{s}$, larger fans having larger capabilities than smaller fans. Very small fans $(<10 \mathrm{~mm})$ are impractical because they are friction-dominated. Below some threshold, even a large number, or a very dense array, of fans is ineffective.

Using COMSOL Multiphysics, a two-dimensional model comprising a skin layer, an undergarment layer and an outer textile layer with a ribbon of micro-fans was constructed. The model was consequently used to determine the convective and evaporative heat

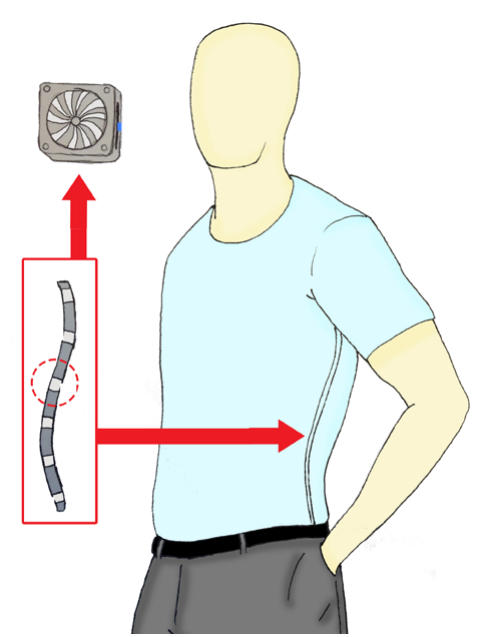

Figure 1: Wearable convective cooling system.

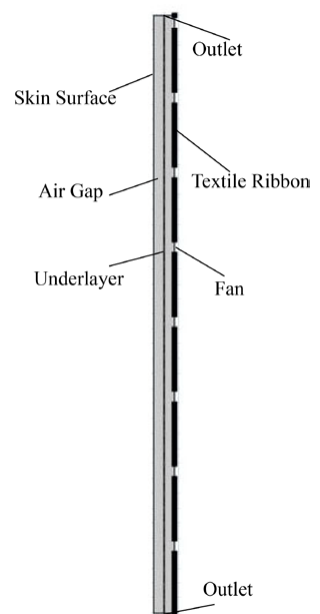

Figure 2: 2 dimensional models of wearable convective cool systems in COMSOL multiphysics.

transfer coefficients of various configurations of the micro fans in the ribbon (Figure 2). The governing equations are shown as Equation 1 to 3 [20] for convective heat transfer and (4) to (7) for evaporative heat transfer. The following configurations were studied: 4 fans of $1 \mathrm{~cm}$ size $(4 \times 1), 4$ fans of $2 \mathrm{~cm}$ size $(4 \times 2)$ and 8 fans of $1 \mathrm{~cm}$ size $(8 \times 1)$. The specifications of these fans would allow for higher flows with larger size fans. The air gaps between the skin surface and the undergarment layer was set at $3 \mathrm{~mm}, 7 \mathrm{~mm}$ and $11 \mathrm{~mm}$ respectively. The distance from the fan to the skin surface was kept at $14 \mathrm{~mm}$ in all cases. The inlet airflow velocities at the fans were set at $0.25 \mathrm{~m} / \mathrm{s}, 0.5 \mathrm{~m} / \mathrm{s}, 0.75 \mathrm{~m} / \mathrm{s}$ and 1.0 $\mathrm{m} / \mathrm{s}$. The software settings, computation procedures and methods of numerical integration to obtain the average convective and evaporative heat transfer coefficients in the COMSOL Multiphysics are given in our previous study [19].

$$
\begin{aligned}
& \rho C_{\mathrm{p}} \mathrm{v} \nabla \mathrm{T}=\nabla(\mathrm{k} \nabla \mathrm{T})+\mathrm{Q}_{\text {gen }} \\
& \nabla(\rho \mathrm{v})=0 \\
& \rho(\mathrm{v} \cdot \nabla) \mathrm{v}=\nabla\left\{-\mathrm{pI}+\mu\left[\nabla \mathrm{v}+(\nabla \mathrm{v})^{\mathrm{T}}\right]-\frac{2}{3} \mu(\nabla \mathrm{v}) \mathrm{I}\right\}+\mathrm{F} \\
& \mathrm{J}=-\mathrm{D} \nabla \mathrm{c}+\mathrm{v} \cdot \mathrm{c} \\
& \nabla(-\mathrm{D} \nabla \mathrm{c})+\mathrm{v} \nabla \mathrm{c}=\mathrm{R} \\
& \mathrm{Q}_{\text {evap }}=\mathrm{J} \times \lambda \\
& \lambda=80776.98-299.95 \mathrm{~T}+0.91 \mathrm{~T}^{2}-0.001 \mathrm{~T}^{3}
\end{aligned}
$$

Where, $\rho$ is the density of air $\left(\mathrm{kg} / \mathrm{m}^{3}\right)$; $\mathrm{c}_{\mathrm{p}}$ is the thermal capacity $(\mathrm{J} /$ $\mathrm{kg} \cdot \mathrm{m}) ; \mathrm{T}$ is the temperature of air (K); $\mathrm{k}$ is the thermal conductivity $(\mathrm{W} / \mathrm{m} \cdot \mathrm{K}) ; \mathrm{Q}_{\text {gen }}$ is the heat generation in the system $\left(\mathrm{W} / \mathrm{m}^{3}\right) ; \mathrm{v}$ is the air velocity $(\mathrm{m} / \mathrm{s}) ; \mu$ is the dynamic viscosity of air $(\mathrm{Kg} / \mathrm{m} \cdot \mathrm{s})$; I is the identity matrix; $\mathrm{p}$ is the air pressure $(\mathrm{Pa})$ and $\mathrm{F}$ is the body force $(\mathrm{N} /$ $\left.\mathrm{m}^{3}\right)$; $\mathrm{J}$ is the is moisture vapor flux $\left(\mathrm{mol} / \mathrm{m}^{2} \cdot \mathrm{s}\right)$ and $\mathrm{D}$ is the diffusion coefficient $(1 / \mathrm{s})$; $\mathrm{v}$ is the air velocity $(\mathrm{m} / \mathrm{s})$; $\mathrm{c}$ is the concentration of moisture in the air; $\mathrm{R}$ is the reaction rate of vapor $\left(\mathrm{mol} / \mathrm{m}^{3} \mathrm{~s}\right) \mathrm{Q}_{\text {evap }}$ is the evaporative heat flux at the skin surface; $\lambda$ is the latent heat of water from liquid phase to gas phase ( $/ \mathrm{mol}$, valid at $248.15 \mathrm{~K}$ to $313.15 \mathrm{~K}$ ); For our simulations, $\mathrm{Q}_{\text {gen }}$ and $\mathrm{F}$ are assumed to be zero as the dominant forces are due to viscosity and there is no heat being generated in the air gap. 
Citation: Sun Y, Jasper WJ, DenHartog EA (2015) Effects of Air Velocity, Air Gap Thickness and Configuration on Heat Transfer of a Wearable Convective Cooling System. J Textile Sci Eng 5: 227. doi:10.4172/2165-8064.1000227

\section{Regression analysis of average convective/evaporative heat transfer coefficients versus inlet airflow velocity}

A regression analysis on the relationship between the convective/ evaporative heat transfer coefficients and the input air velocity was conducted on the simulation results. In the literature, the relationship between the convective heat transfer coefficient and the inlet air velocity is given as a power function, as shown in Equation (8) [21,22]:

$$
\mathrm{h}=\mathrm{A} \cdot \mathrm{v}^{\mathrm{B}}
$$

Where, $\mathrm{v}$ is the velocity of the inlet airflow $(\mathrm{m} / \mathrm{s})$ and $\mathrm{h}$ is the convective or evaporative heat transfer coefficient $\left(\mathrm{W} / \mathrm{m}^{2} \cdot \mathrm{K}\right)$. A and $\mathrm{B}$ are constants which can be obtained from a regression analysis. The literature suggests that the value of $\mathrm{A}$ is around 7-14 and the value of $\mathrm{B}$ ranged from $0.5-0.8[21,22]$.

\section{Compare average convective/evaporative heat transfer coefficients of models of different configurations}

The average convective and evaporative heat transfer coefficients were obtained by determining the normal numerical average of the coefficients over the skin surface. The average convective and evaporative heat transfer coefficients of the $8 \times 1$ fans models and then $4 \times 2$ fans models were compared with those of the $4 \times 1$ fans to evaluate the effects of increasing fan number and size.

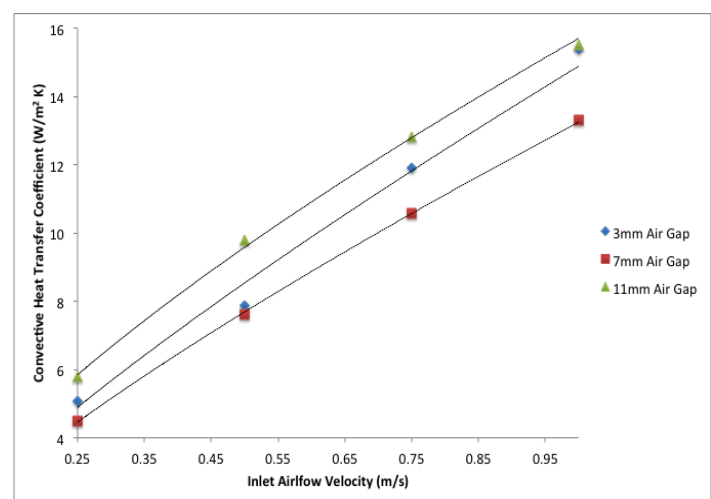

(a)

\section{Results}

The local convective and evaporative heat transfer coefficients across the skin surface have been described previously [19]. Figures 3-5 show the simulation results of the average coefficients across the skin surface of convective and evaporative heat transfer versus inlet air velocities for different thicknesses of the air gaps. The results of the regression analysis on the relationship between the convective and evaporative heat transfer coefficient with inlet air velocity are shown in Tables 1 and 2 respectively. The constant $B$ that was obtained ranged from 0.5 to 0.8 , a little larger than the values reported in literature (0.5-0.6) [21]. The regression analysis of the evaporative heat transfer coefficient versus inlet air velocities gave an $\mathrm{R}^{2}$ value greater than 0.99 for all simulations but one. The B values were similar for the convective heat transfer and evaporative heat transfer.

Furthermore, at inlet air velocities ranging from $0.25 \mathrm{~m} / \mathrm{s}$ to 0.75 $\mathrm{m} / \mathrm{s}$, the convective and evaporative heat transfer coefficients in the 11 $\mathrm{mm}$ air gap was higher than those in $3 \mathrm{~mm}$ and $7 \mathrm{~mm}$ air gaps. When the inlet airflow increased to $1 \mathrm{~m} / \mathrm{s}$, we found that both of the convective and evaporative heat transfer in the $3 \mathrm{~mm}$ air gaps increased to the same or even higher levels as at the $11 \mathrm{~mm}$ air gaps. In other words, at $1 \mathrm{~m} / \mathrm{s}$ inlet airflow, a $7 \mathrm{~mm}$ air gap had the lowest heat removal rates.

The ratios of the convective and evaporative heat transfer

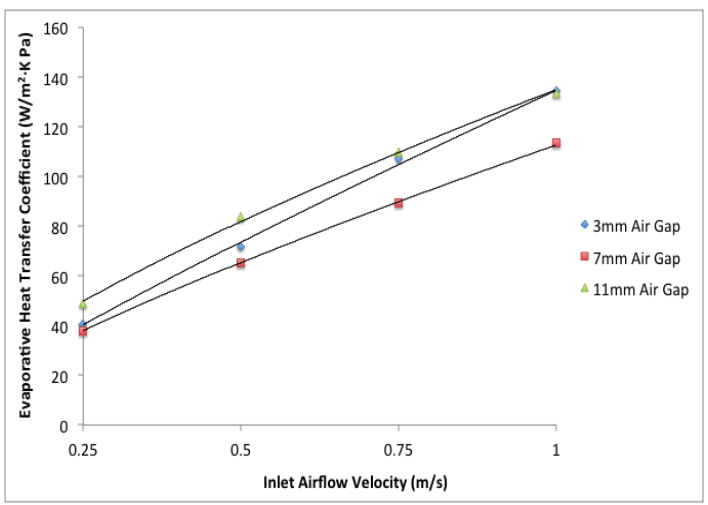

(b)

Figure 3: Average convective (a) and evaporative (b) heat transfer coefficients versus inlet air velocities and regression analysis at $81 \mathrm{~cm}$ fans models.

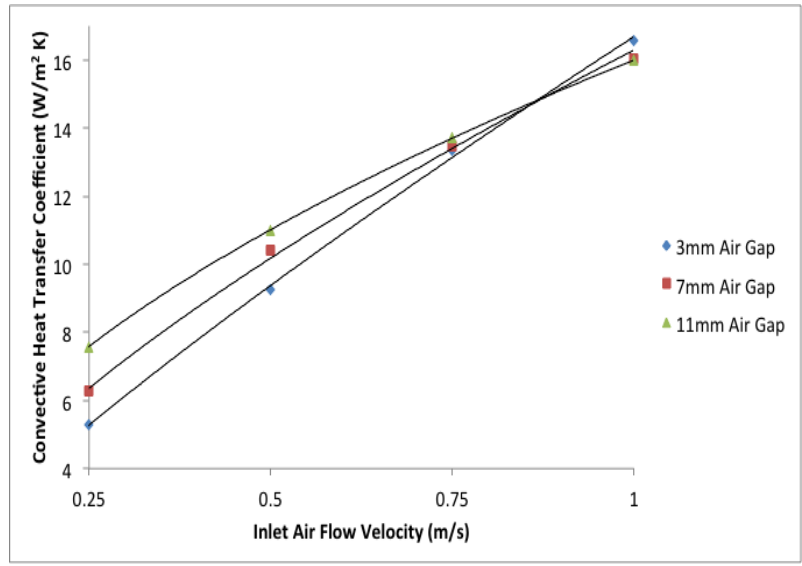

(a)

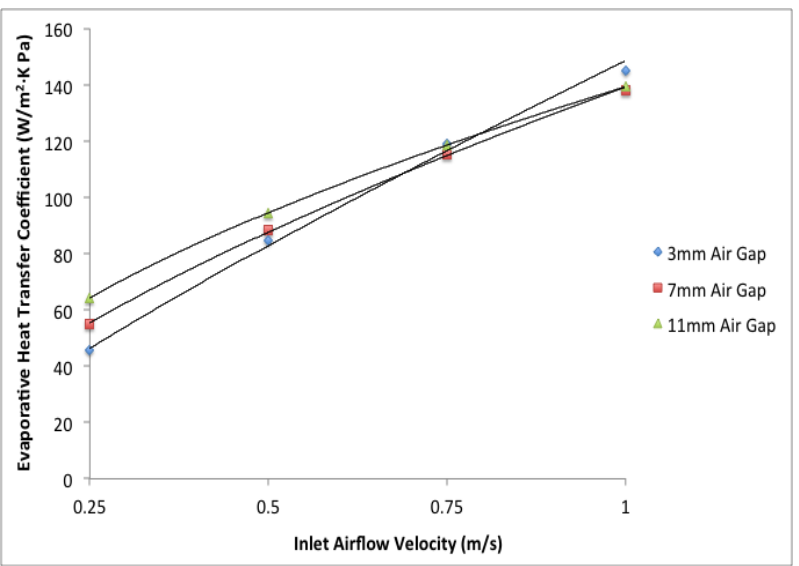

(b)

Figure 4: Average convective (a) and evaporative (b) heat transfer coefficients versus inlet air velocities and regression analysis at $42 \mathrm{~cm}$ fans models. 


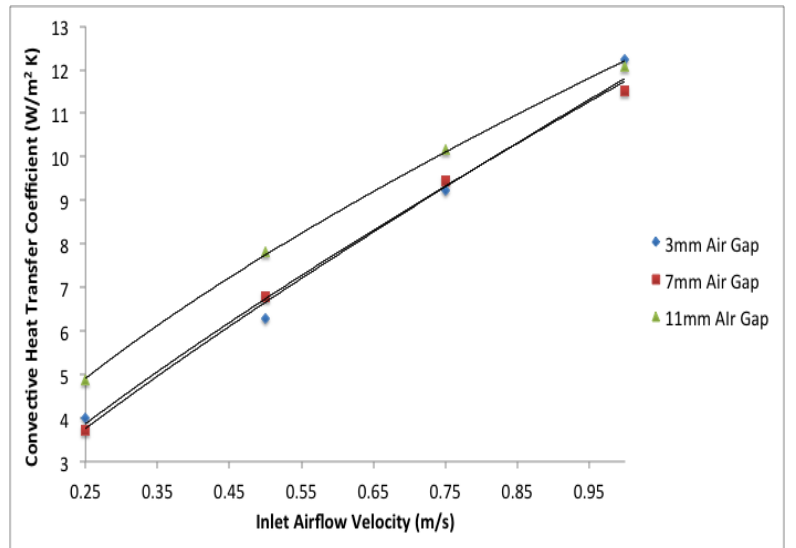

(a)

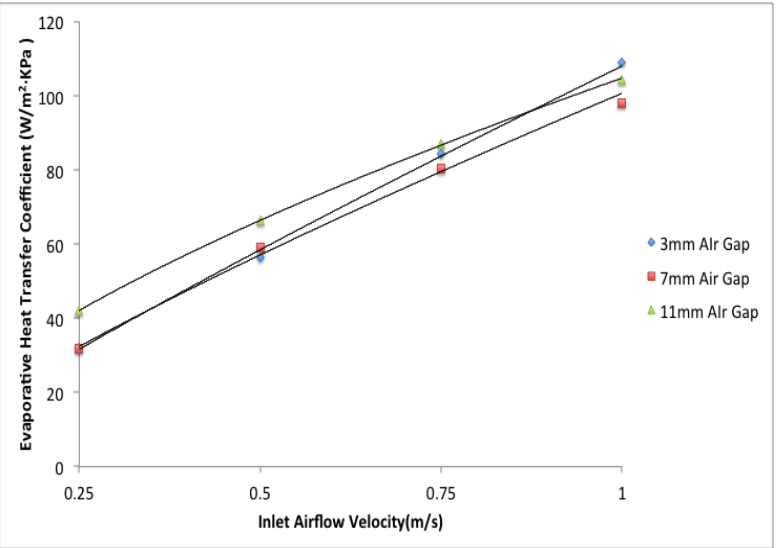

(b)

Figure 5: Average convective (a) and evaporative (b) heat transfer coefficients versus inlet air velocities and regression analysis at $41 \mathrm{~cm}$ fans models.

\begin{tabular}{|c|c|c|c|c|}
\hline Configuration & $\begin{array}{l}\text { Air Gap } \\
\text { Thickness } \\
\text { (mm) }\end{array}$ & Constant $A$ & Constant $B$ & $\mathbf{R}^{2}$ \\
\hline \multirow[t]{3}{*}{$81 \mathrm{~cm}$-fan } & 3 & 14.89 & 0.803 & 0.987 \\
\hline & 7 & 12.25 & 0.786 & 0.999 \\
\hline & 11 & 13.87 & 0.773 & 0.999 \\
\hline \multirow[t]{3}{*}{$41 \mathrm{~cm}$-fan } & 3 & 11.73 & 0.801 & 0.989 \\
\hline & 7 & 11.80 & 0.826 & 0.998 \\
\hline & 11 & 12.21 & 0.652 & 0.999 \\
\hline \multirow[t]{3}{*}{$42 \mathrm{~cm}$-fan } & 3 & 16.68 & 0.831 & 0.999 \\
\hline & 5 & 16.29 & 0.678 & 0.998 \\
\hline & 11 & 16.00 & 0.539 & 0.999 \\
\hline
\end{tabular}

Table 1: Results of regression analysis on the convective heat transfer coefficients $\left(\mathrm{w} / \mathrm{m}^{2} \cdot \mathrm{k}\right)$ versus inlet air flow velocities.

\begin{tabular}{|c|c|c|c|c|}
\hline Configuration & $\begin{array}{l}\text { Air Gap } \\
\text { Thickness } \\
\text { (mm) }\end{array}$ & Constant $A$ & Constant $B$ & $\mathbf{R}^{2}$ \\
\hline \multirow[t]{3}{*}{$81 \mathrm{~cm}-f a n$} & 3 & 134.57 & 0.886 & 0.998 \\
\hline & 7 & 112.16 & 0.829 & 0.996 \\
\hline & 11 & 134.84 & 0.658 & 0.999 \\
\hline \multirow[t]{3}{*}{$41 \mathrm{~cm}-\mathrm{fan}$} & 3 & 107.88 & 0.871 & 0.999 \\
\hline & 7 & 100.55 & 0.787 & 0.999 \\
\hline & 11 & 104.65 & 0.721 & 0.999 \\
\hline \multirow[t]{3}{*}{$42 \mathrm{~cm}$-fan } & 3 & 148.58 & 0.842 & 0.998 \\
\hline & 5 & 139.19 & 0.667 & 0.999 \\
\hline & 11 & 139.26 & 0.559 & 0.999 \\
\hline
\end{tabular}

Table 2: Results of regression analysis on the evaporative heat transfer coefficients $\left(\mathrm{w} / \mathrm{m}^{2} \bullet \mathrm{kpa}\right)$ versus inlet air flow velocities.

coefficients for the three different models are shown in Table 3. In our $2 \mathrm{D}$ configuration a $100 \%$ increase in fan surface area represented a $100 \%$ increase in total flow, as the $\mathrm{z}$ direction extended continuously. Although the total flow of the $8 \times 1$ and $4 \times 2$ models is two times that of the $4 \times 1$ model, the ratios of the convective and evaporative heat transfer coefficients were only around 1.1-1.7. In the velocity regression equations the exponents, ranging from 0.6 to 0.8 , also indicated that a $100 \%$ increase in flow, in that case via increasing velocity, leads to a smaller increase in heat transfer, based on that a factor of 1.5 to 1.7 could be expected. The results in Table 3, however, show much lower values in most cases. This suggests that the efficiency of increasing flow

\begin{tabular}{|c|c|c|c|c|c|}
\hline \multirow[t]{2}{*}{ Inlet Air Flow } & \multirow[t]{2}{*}{ Air Gap } & \multicolumn{2}{|c|}{$\begin{array}{c}\text { Ratio of } 8 \times 1 \text { Models to } \\
4 \times 1 \text { models }\end{array}$} & \multicolumn{2}{|c|}{$\begin{array}{c}\text { Ratio of } 4 \times 2 \text { Models to } \\
4 \times 1 \text { models }\end{array}$} \\
\hline & & Convective & Evaporative & Convective & Evaporative \\
\hline \multirow{3}{*}{$0.25 \mathrm{~m} / \mathrm{s}$} & $3 \mathrm{~mm}$ & 1.27 & 1.27 & 1.32 & 1.42 \\
\hline & $7 \mathrm{~mm}$ & 1.21 & 1.20 & 1.70 & 1.73 \\
\hline & $11 \mathrm{~mm}$ & 1.18 & 1.17 & 1.55 & 1.53 \\
\hline \multirow{3}{*}{$0.5 \mathrm{~m} / \mathrm{s}$} & $3 \mathrm{~mm}$ & 1.25 & 1.27 & 1.47 & 1.50 \\
\hline & $7 \mathrm{~mm}$ & 1.12 & 1.10 & 1.54 & 1.50 \\
\hline & $11 \mathrm{~mm}$ & 1.25 & 1.26 & 1.41 & 1.43 \\
\hline \multirow{3}{*}{$0.75 \mathrm{~m} / \mathrm{s}$} & $3 \mathrm{~mm}$ & 1.29 & 1.27 & 1.45 & 1.41 \\
\hline & $7 \mathrm{~mm}$ & 1.12 & 1.11 & 1.42 & 1.43 \\
\hline & $11 \mathrm{~mm}$ & 1.26 & 1.26 & 1.35 & 1.36 \\
\hline \multirow{3}{*}{$1 \mathrm{~m} / \mathrm{s}$} & $3 \mathrm{~mm}$ & 1.26 & 1.23 & 1.35 & 1.33 \\
\hline & $7 \mathrm{~mm}$ & 1.15 & 1.16 & 1.39 & 1.41 \\
\hline & $11 \mathrm{~mm}$ & 1.28 & 1.28 & 1.32 & 1.34 \\
\hline
\end{tabular}

Table 3: Compare of convective and evaporative heat transfer coefficients at difference configured models.

through increased fan area is less efficient than increasing the wind speed.

The ratios of the evaporative to convective heat transfer coefficients are shown in Table 4 . Based on these ratios, the Woodcock permeability index $\left(i_{m}\right)$ as shown in Equation (9) [23] of our cooling system could be obtained. It showed that the ratios of convective to evaporative heat transfer coefficients and the Woodcock permeability indices, as shown in Table 5, of our cooling system fell in a narrow range and were independent of the inlet airflow velocity and configurations of the cooling system. The average value of these ratios and permeability indices were $8.63 \mathrm{~K} / \mathrm{kPa}$ and 0.52 with standard deviation of $0.25 \mathrm{~K} / \mathrm{kPa}$ and 0.02 respectively.

$$
\mathrm{i}_{\mathrm{m}}=\frac{\mathrm{I}_{\mathrm{t}}}{16.5 \times \mathrm{R}_{\mathrm{t}}}=\frac{\mathrm{h}_{\mathrm{e}}}{16.5 \times \mathrm{h}_{\mathrm{c}}}
$$

Where, $\mathrm{i}_{\mathrm{m}}$ is the permeability index; $\mathrm{I}_{\mathrm{t}}$ is the total thermal insulation $\left(\mathrm{m}^{2} \cdot \mathrm{K} / \mathrm{W}\right)$ and $\mathrm{R}_{\mathrm{t}}$ is the total evaporative resistance $\left(\mathrm{m}^{2} \cdot \mathrm{kPa} / \mathrm{W}\right)$;

\section{Discussion}

The simulations presented here were aimed to support design and development of a micro-fan system that may be integrated into everyday clothing and would need to provide low to moderate levels 


\begin{tabular}{|c|c|c|c|c|c|}
\hline Inlet Air Flow & Air Gap & $\begin{array}{c}41 \mathrm{~cm}-F a n s \\
\text { Models }\end{array}$ & $\begin{array}{l}81 \mathrm{~cm}-\text { Fans } \\
\text { Models }\end{array}$ & $\begin{array}{c}42 \mathrm{~cm}-F a n s \\
\text { Models }\end{array}$ & Evaporative \\
\hline \multirow{3}{*}{$0.25 \mathrm{~m} / \mathrm{s}$} & $3 \mathrm{~mm}$ & 8.01 & 7.99 & 8.62 & 1.42 \\
\hline & $7 \mathrm{~mm}$ & 8.53 & 8.48 & 8.72 & 1.73 \\
\hline & $11 \mathrm{~mm}$ & 8.60 & 8.50 & 8.47 & 1.53 \\
\hline \multirow{3}{*}{$0.5 \mathrm{~m} / \mathrm{s}$} & $3 \mathrm{~mm}$ & 8.98 & 9.09 & 9.15 & 1.50 \\
\hline & $7 \mathrm{~mm}$ & 8.72 & 8.55 & 8.50 & 1.50 \\
\hline & $11 \mathrm{~mm}$ & 8.47 & 8.55 & 8.58 & 1.43 \\
\hline \multirow{3}{*}{$0.75 \mathrm{~m} / \mathrm{s}$} & $3 \mathrm{~mm}$ & 9.12 & 8.97 & 8.89 & 1.41 \\
\hline & $7 \mathrm{~mm}$ & 8.49 & 8.43 & 8.56 & 1.43 \\
\hline & $11 \mathrm{~mm}$ & 8.57 & 8.54 & 8.65 & 1.36 \\
\hline \multirow{3}{*}{$1 \mathrm{~m} / \mathrm{s}$} & $3 \mathrm{~mm}$ & 8.91 & 8.71 & 8.74 & 1.33 \\
\hline & $7 \mathrm{~mm}$ & 8.49 & 8.52 & 8.61 & 1.41 \\
\hline & $11 \mathrm{~mm}$ & 8.62 & 8.60 & 8.71 & 1.34 \\
\hline
\end{tabular}

Table 4: Ratio of convective heat transfer coefficients to evaporative heat transfer coefficients $(\mathrm{k} / \mathrm{kpa})$.

\begin{tabular}{|c|c|c|c|c|c|}
\hline Inlet Air Flow & Air Gap & $\begin{array}{c}41 \mathrm{~cm}-\text { Fans } \\
\text { Models }\end{array}$ & $\begin{array}{l}81 \mathrm{~cm}-\text { Fans } \\
\text { Models }\end{array}$ & $\begin{array}{c}42 \mathrm{~cm}-\text { Fans } \\
\text { Models }\end{array}$ & Evaporative \\
\hline \multirow{3}{*}{$0.25 \mathrm{~m} / \mathrm{s}$} & $3 \mathrm{~mm}$ & 0.49 & 0.48 & 0.52 & 1.42 \\
\hline & $7 \mathrm{~mm}$ & 0.52 & 0.51 & 0.53 & 1.73 \\
\hline & $11 \mathrm{~mm}$ & 0.52 & 0.52 & 0.51 & 1.53 \\
\hline \multirow{3}{*}{$0.5 \mathrm{~m} / \mathrm{s}$} & $3 \mathrm{~mm}$ & 0.54 & 0.55 & 0.55 & 1.50 \\
\hline & $7 \mathrm{~mm}$ & 0.53 & 0.52 & 0.52 & 1.50 \\
\hline & $11 \mathrm{~mm}$ & 0.51 & 0.52 & 0.52 & 1.43 \\
\hline \multirow{3}{*}{$0.75 \mathrm{~m} / \mathrm{s}$} & $3 \mathrm{~mm}$ & 0.55 & 0.54 & 0.54 & 1.41 \\
\hline & $7 \mathrm{~mm}$ & 0.51 & 0.51 & 0.52 & 1.43 \\
\hline & $11 \mathrm{~mm}$ & 0.52 & 0.52 & 0.52 & 1.36 \\
\hline \multirow{3}{*}{$1 \mathrm{~m} / \mathrm{s}$} & $3 \mathrm{~mm}$ & 0.54 & 0.53 & 0.53 & 1.33 \\
\hline & $7 \mathrm{~mm}$ & 0.51 & 0.52 & 0.52 & 1.41 \\
\hline & $11 \mathrm{~mm}$ & 0.52 & 0.52 & 0.53 & 1.34 \\
\hline
\end{tabular}

Table 5: Woodcock permeability indices of wearable convective cooling systems.

of cooling to expand the comfort temperature range. Other studies have focused on using fans to provide cooling, mostly under protective clothing [5] or under hot working conditions [9]. In our study the focus was to provide limited cooling to enhance the comfort range of everyday clothing.

Figures 3-5 show that higher inlet airflows result in higher heat transfer, which agrees with many other studies [21-25]. The regression analysis of the convection/evaporative heat transfer coefficient versus inlet air velocity showed very good correlation as a power function, with mostly $\mathrm{R}^{2}>0.99$ (one $\mathrm{R}^{2}$ value is 0.987 ). This suggested that the regression equations were a reliable tool in predicting the convective and evaporative heat transfer coefficients for inlet air velocities in the range of $0.25 \mathrm{~m} / \mathrm{s}$ to $1 \mathrm{~m} / \mathrm{s}$. The values of $B$ in the convective heat transfer regression equation are similar in value to those in the evaporative heat transfer regression equation, indicating that the convective and evaporative heat transfers are fully coupled. The variation in the value of B with different air gap thicknesses implies that the air gap thickness affects the system's heat removal capability. The constant B in our study was higher than the values found in the literature $[21,22]$. There were some major differences between our studies and the literature that may help understand these differences. Firstly, the geometry was different as the $2 \mathrm{D}$ system is different from the manikin and human studies from the literature $[21,22]$. Furthermore, these studies were performed on nude/bare surfaces and in our study we focused on the impact of two clothing layers on the heat transfer. Finally, the airflow patterns were different in our study compared to the studies in the literature, where a uniform air flow field was used as opposed to the locally forced convective air flow from the fans in this study. Our previous study showed large differences in local heat transfer coefficients [19] whereas we have focused on average heat transfer across the skin surface in this study.

In this study, we analyzed three different configurations of the cooling system. The configurations were different in the quantity and size of fans in the textile ribbons. The air velocity and flow were expected to affect the convective and evaporative heat transfer. In order to increase the flow, one could add more fans into the textile ribbon or use fans with a larger area. The simulation results showed that, doubling the flow, either by increasing the fans diameter or by doubling the number of fans, did not double the convective and evaporative heat transfer coefficients. The reason is that the convective/ evaporative heat transfer coefficients at the skin were mostly dependent on the velocity of local parallel airflow near the skin surface. Doubling the flow caused higher air velocities of close to the skin, but did not double these velocities and, therefore, did not lead to a doubling in heat transfer rate.

Our simulation results show that the air gap between the skin surface and the undergarment is an important parameter that influences the convective and evaporative heat transfer. These effects are demonstrated by studying the normalized air velocities, defined as the ratio of the local air velocity to the inlet air velocity. As shown in Figures $6 \mathrm{a}$ and $6 \mathrm{~b}$, at $0.25 \mathrm{~m} / \mathrm{s}$ inlet air velocity, the normalized local air velocity inside $3 \mathrm{~mm}$ air gap was very low while inside the $11 \mathrm{~mm}$ air gap, the normalized local air velocity was almost equal to one (Figure 6c). At a low inlet air velocity, stronger flows developed in the larger air gaps only. Therefore, at lower inlet air velocity, convective and evaporative heat transfer coefficients at the skin were higher with the $11 \mathrm{~mm}$ air gaps than those with the $3 \mathrm{~mm}$ and $7 \mathrm{~mm}$ air gaps. When the inlet air velocity increased to $1 \mathrm{~m} / \mathrm{s}$, as shown in Figures $7 \mathrm{a}$ and $7 \mathrm{~b}$, the normalized local air velocity inside the $3 \mathrm{~mm}$ air gap was close to one as well, indicating the local air velocity inside the $3 \mathrm{~mm}$ air gap was much more similar to the velocity in the $11 \mathrm{~mm}$ air gap as shown in Figure $7 \mathrm{c}$. As a consequence at $1 \mathrm{~m} / \mathrm{s}$ inlet air velocity, the convective and evaporative heat transfer coefficients at $3 \mathrm{~mm}$ air gap were at the same level as those at $11 \mathrm{~mm}$ air gap. These results suggest that micro fans at $1 \mathrm{~m} / \mathrm{s}$ air velocity would provide sufficient pressure to force the flow through the undergarment layer. In practice, the exact velocity at which sufficient amounts of air flows through the undergarment may be highly dependent on the air permeability of the material, which was not varied in this study.

Our results regarding the effects of the air gap thickness to the convective heat transfer coefficient were different from results in a previous simulation study $[24,25]$. The main difference was that Ding et al. used an air flow parallel to the clothing layer while in our study the fans forced air perpendicular to the clothing layer and into the air gap. Ding et al. designed the system so that the air flow in the air gap was a result from the air permeability of the clothing, leading to much lower local air velocities under the clothing, while we obtained higher local velocities, up to $1 \mathrm{~m} / \mathrm{s}$, in our study.

It was shown that the Woodcock permeability indices of our cooling system were not affected by the air velocities in our study. These results in our study did not agree with the values Woodcock found, which indicated that the permeability indices are higher at the higher air velocity. By reviewing the definition of the Woodcock permeability index as shown in Equation 9, the permeability index is determined solely by the ratio of evaporative to convective heat transfer coefficients. As we discussed earlier, the convective and evaporative heat transfer are fully coupled and the increase of air velocity would increase both of 


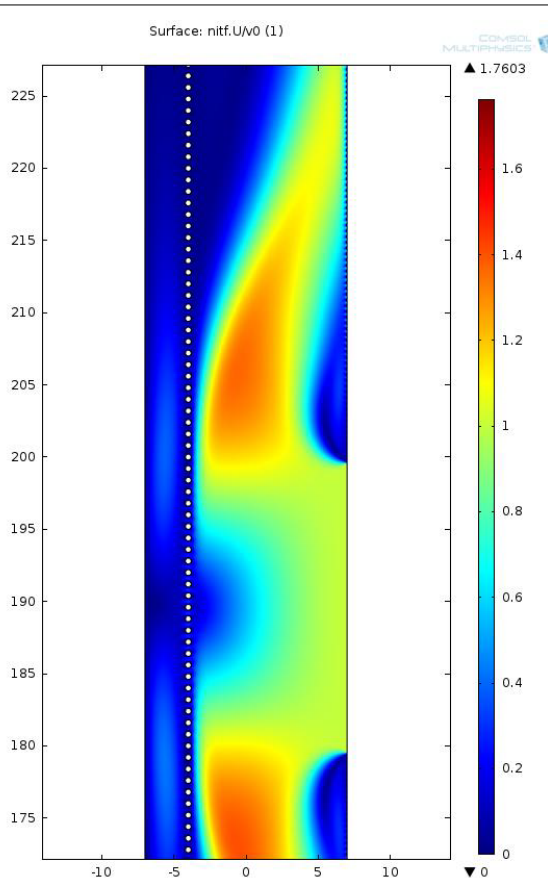

(a)

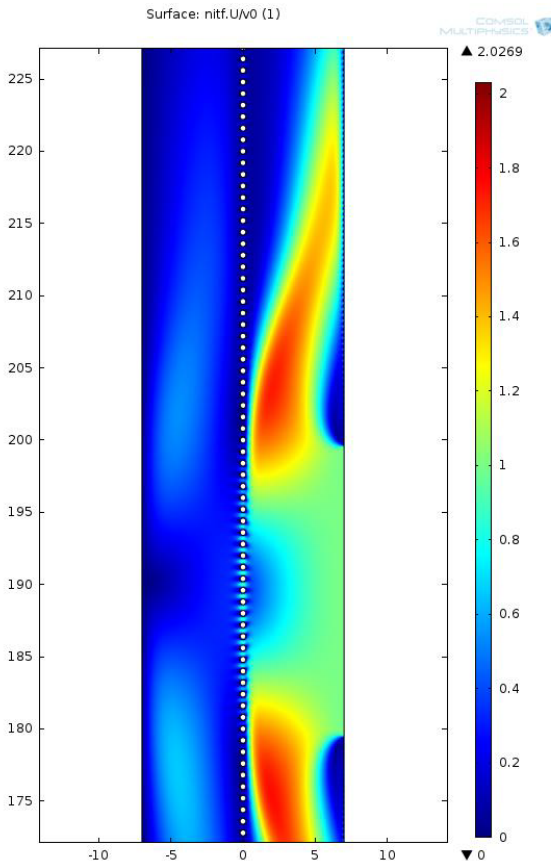

(b)

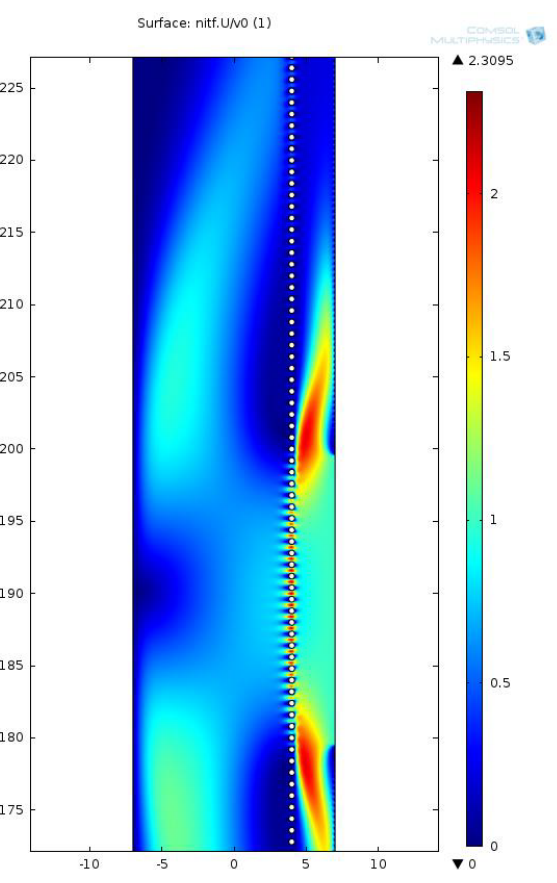

(c)

Figure 6: Local normalized local air velocity at (a) $3 \mathrm{~mm}$ air gap; (b) $7 \mathrm{~mm}$ air gap and (c) $11 \mathrm{~mm}$ air gap at $0.25 \mathrm{~m} / \mathrm{s}$ inlet airflows.

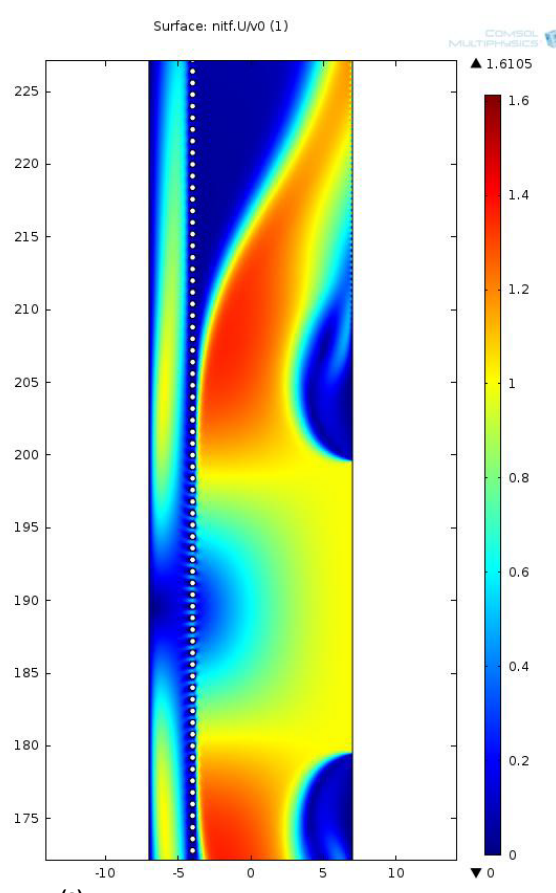

(a)

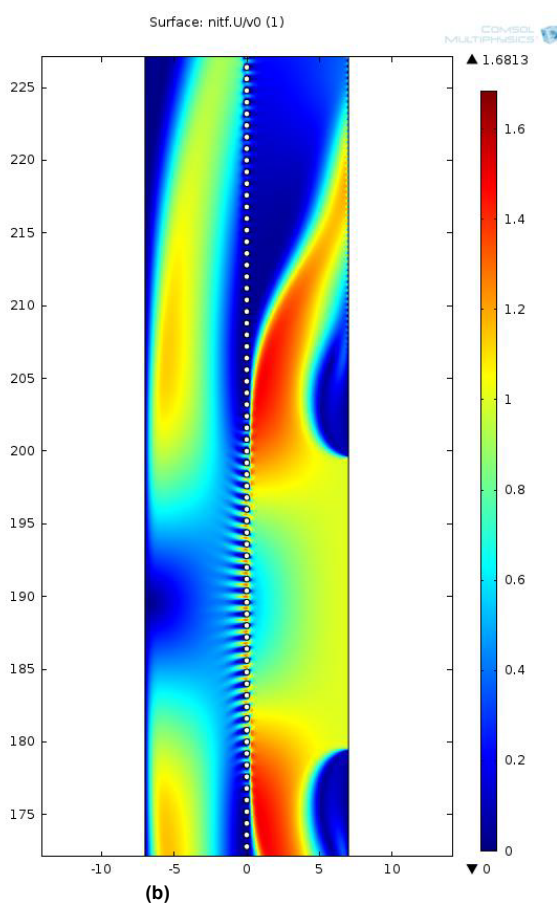

(b)

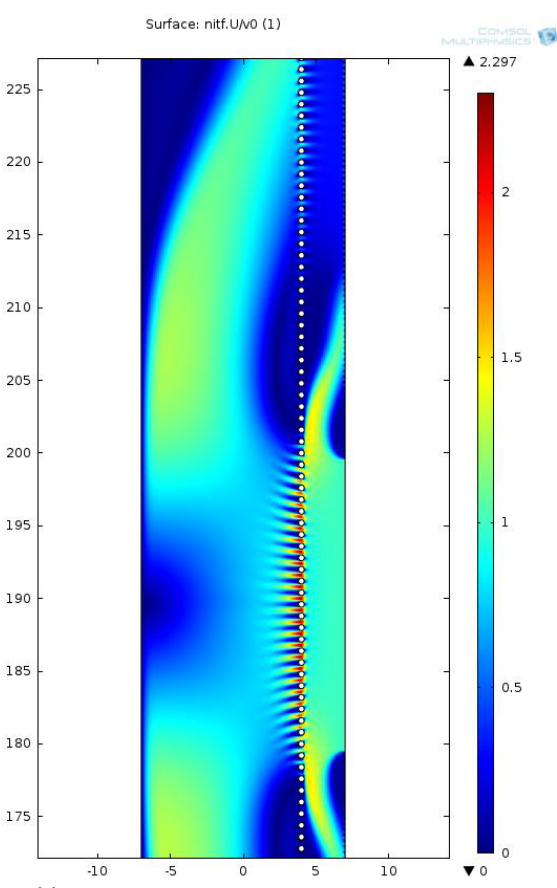

(c)

Figure 7: Local normalized local air velocity at (a) $3 \mathrm{~mm}$ air gap; (b) $7 \mathrm{~mm}$ air gap and (c) $11 \mathrm{~mm}$ air gap at $1 \mathrm{~m} / \mathrm{s}$ inletairflows.

the evaporative and convective heat transfer coefficients at the almost same magnitude. Woodcock measured the evaporative and total dry heat fluxes on a dry bulb thermometer and therefore radiative heat exchange influenced the permeability index. Indeed other authors have confirmed that the implicit inclusion of the radiative heat exchange in Woodcock's work caused the dependence on air velocity [26,27]. In our numerical simulations we were able to separate those effects and a $\mathrm{sF}$ ratio of evaporative and convective heat transfer was found, within the range of the literature [26,27], further providing support in validation of the simulations. Such a separation of convective and 
radiant heat loss would be very difficult to obtain experimentally and tis modeling method would also allow further expansion ith the radiant heat transfer to further study the Woodcock permeability index under these forced convection conditions. It is reasonable to assert that the air velocity does not influence the ratio of convective to evaporative heat loss, however in practice such a relationship will be obtained due to the radiant heal loss effects [26,27] The ratios of the evaporative and heat transfer coefficients and the permeability indices were also found independent of the air gap thickness and configurations of cooling system, which indicated that the thickness of air gaps, fan size and quantity of fans did not affect the coupling of the evaporative and convective heat transfer.

The experimental study most similar to our numerical simulation work so far, was carried out by Lu et al. [5]. In their study, four 10 $\mathrm{cm}$ fans were integrated into the clothing: two in the front and two in the back on the torso. It was indicated that the convective and evaporative heat transfer were significantly improved. However, the average convective and evaporative heat transfer coefficients in their study were around $13.33 \mathrm{~W} / \mathrm{m}^{2} \cdot \mathrm{K}$ and $111.11 \mathrm{~W} / \mathrm{m}^{2} \cdot \mathrm{kPa}$, similar to our results at $1 \mathrm{~m} / \mathrm{s}$ inlet air velocity $\left(11.53\right.$ to $16.00 \mathrm{~W} / \mathrm{m}^{2} \cdot \mathrm{K}$ and 97.87 to $111.11 \mathrm{~W} / \mathrm{m}^{2} \cdot \mathrm{kPa}$, respectively) [19]. Consequently, our cooling system showed the advantages of similar cooling capability but at a smaller size, making the system potentially more wearable for every-day wear. On the other hand, our system will provide a more limited cooling over the entire torso as only a limited amount of ribbons with micro-fans should be used to maximize wearability. Lu et al. [5] achieved a cooling of $60 \mathrm{~W} / \mathrm{m}^{2}$ to $80 \mathrm{~W} / \mathrm{m}^{2}$ whereas, our systems was designed to only increase the comfort range a few degrees Celsius, requiring only 20-30 $\mathrm{W} / \mathrm{m}^{2}$ of cooling. In all, the ribbon with micro-fans does provide the capability to cool the body through a wearable system allowing towear normal clothing in an extended comfort range.

\section{Conclusions}

The effects of inlet air velocities and configurations of cooling systems were investigated. Increasing the inlet air velocity increased the convective and evaporative heat transfer coefficients. The correlation between the inlet air velocities with the convective or evaporative heat transfer coefficients correlated well with known power functions. Regression was used to obtain the average convective or evaporative heat transfer coefficient at various inlet air velocity levels.

The effects of the fan size and number were also studied. Doubling the size or quantity of fans did not double the convective and evaporative heat transfer coefficient. At low inlet air velocity, larger air gaps will induce higher heat transfer coefficients and at high inlet air velocity, both small and larger air gaps will induce higher heat removal capability.

\section{References}

1. Yazdi MM, Sheikhzadeh M (2014) Personal Cooling Garments: a Review. The Journal of the Textile Institute 105: 1231-1250.

2. Mondal S (2008) Phase Change Materials for Smart Textile-An Overview. Applied Thermal Engineering 28: 1536-1550.

3. Shim H, McCullough EA, Jones BW (2001) Using phase change materials in clothing. Textile Research Journal 71: 495-502.

4. Salaun F, Devaux E, Bourbigot S, Rumeau P (2010) Development of phase change materials in clothing part I: formulation of microencapsulated phase change. Textile Research Journal 80: 195-205.

5. Lu Y, Wei F, Lai D, Wang F, Song G, et al. (2015) A Novel Personal Cooling System (PCS) Incorporated with Phase Change Materials (PCMs) and Ventilation Fans: An Investigation on Its Cooling Efficiency. Journal of Thermal Biology 52: 137-146.
6. Delkumburewatte GB, Dias T (2012) Wearable Cooling System to Mange Heat in Protective Clothing. Journal of the Textile Institute 103: 483-489.

7. Ernst TC, Garimella S (2009) Wearable engine-driven vapor compression cooling system for elevated ambient. Journal of Thermal Science and Engineering Applications.

8. Flouris AD, Cheung SS (2006) Design and control optimization of microclimate liquid cooling systems underneath protective clothing. Annals of Biomedical Engineering 34: 359-372.

9. Ernst TC, Garmella S (2013) Demonstration of a wearable cooling system for elevated ambient temperature duty personnel. Applied Thermal Engineering 60: 316-324.

10. Chen YT, Constable SH, Bomalaski SH (1997) A Lightweight Ambient AirCooling Unit for Use in Hazardous Environments. American Industrial Hygiene Association Journal 58: 10-14.

11. Xu X, Gonzalez J (2011) Determination of the Cooling Capacity for Body Ventilation System. European Journal of Applied Physiology 111: 3155-5160.

12. Chinevere TD, Cadarette BS, Goodman DA, Ely BR, Cheuvront SN, et al. (2008) Efficacy of Body Ventilation System for Reducing Strain in Warm and Hot Climates. European Journal of Applied Physiology 103: 307-314.

13. Hadid A, Yanovich R, Erlich T, Khomenok G, Morgan DS (2008) Effect of a personal ambient ventilation system on physiological strain during heat stress. European journal of Applied Physiology 104: 311-319.

14. Barwood MJ, Newton PS, Tipton MJ (2009) Ventilated vest and tolerance for intermittent exercise in hot dry conditions with military clothing. Aviation. Space and Environmental Medicine 80: 353-359.

15. Reffeltrath PA (2006) Heat stress reduction of helicopter crew wearing ventilated vest Aviation. Space and Environmental Medicine 77: 545-550.

16. Glitzm KJ, Seibel U, Rodhe U, Gerges W, Witzki A, et al. (2015) Reducing heat stress under thermal insulation in protective clothing: microclimate cooling by a physiological method. Ergonomics 58: 1461-1469.

17. Zhao M, Gao C, Wang F, Kuklane K, Holmer I, et al. (2013) A study on local cooling of garments with ventilation fans and openings placed at different torso sites. International Journal of Industrial Ergonomics 43: 232-237.

18. Zhao M, Gao C, Li J, Wang F (2014) Effects of two cooling garments on postexcise thermal comfort of female subjects in the heat. Fiber and Polymers 16 : 1403-1409.

19. Sun Y, Jasper WJ (2015) Numerical Modeling of Heat and Moisture Transfer in a Wearable Convective Cooling System for Human Comfort. Building and Environment 93: 50-62

20. Wendt J (2008) Computational Fluid Dynamics - An Introduction. Springer Science \& Business Media.

21. de Dear RJ, Arens E, Hui Z, Oguro M (1997) Convective and radiative hea transfer coefficients for individual human body segments. International journa of biometeorology 40: 141-156.

22. Holmer I, Nilsson H, Havenith G, Parsons K (1999) Clothing convective hea exchange-proposal for improved prediction in standards and models. Annals of Occupational Hygiene 43: 329-337.

23. Woodcock AH (1962) Moisture transfer in textile systems. Textile Research Journal 32: 628-633

24. Ding D, Tang T, Song G, McDonald A (2011) Characterizing the performance of a single-layer fabric system through a heat and mass transfer model - Part I: Heat and mass transfer model. Textile Research Journal 81: 398-411.

25. Ding D, Tang T, Song G, McDonald, A (2011) Characterizing the performance of a single-layer fabric system through a heat and mass transfer model - Part II: Thermal and evaporative resistances. Textile Research Journal 81: 945-958.

26. Spencer-Smith (1975) the Limitations of Woodcock's Moisture Permeability Index. Textile Research Journal 45: 220-222.

27. Lotens WA (1993) Heat Transfer from humans wearing clothing. Tech University Delft, Netherlands. 